\title{
Review Article \\ Dengue Virus Entry as Target for Antiviral Therapy
}

\author{
Marijke M. F. Alen and Dominique Schols \\ Department of Microbiology and Immunology, Rega Institute for Medical Research, Katholieke Universiteit Leuven, \\ 3000 Leuven, Belgium
}

Correspondence should be addressed to Dominique Schols, dominique.schols@rega.kuleuven.be

Received 26 September 2011; Accepted 10 November 2011

Academic Editor: Jean-Paul Gonzalez

Copyright () 2012 M. M. F. Alen and D. Schols. This is an open access article distributed under the Creative Commons Attribution License, which permits unrestricted use, distribution, and reproduction in any medium, provided the original work is properly cited.

\begin{abstract}
Dengue virus (DENV) infections are expanding worldwide and, because of the lack of a vaccine, the search for antiviral products is imperative. Four serotypes of DENV are described and they all cause a similar disease outcome. It would be interesting to develop an antiviral product that can interact with all four serotypes, prevent host cell infection and subsequent immune activation. DENV entry is thus an interesting target for antiviral therapy. DENV enters the host cell through receptor-mediated endocytosis. Several cellular receptors have been proposed, and DC-SIGN, present on dendritic cells, is considered as the most important DENV receptor until now. Because DENV entry is a target for antiviral therapy, various classes of compounds have been investigated to inhibit this process. In this paper, an overview is given of all the putative DENV receptors, and the most promising DENV entry inhibitors are discussed.
\end{abstract}

\section{Introduction}

Dengue virus (DENV) is a single-stranded, positive-sense enveloped RNA virus of the Flaviviridae family that is transmitted by Aedes aegypti and Aedes albopictus. There exist 4 different serotypes of DENV. Each serotype shares around $65 \%$ of the genome, and, despite of the differences, each serotype causes nearly identical syndromes in humans and circulates in the same ecological niche [1]. Dengue virus causes clinical syndromes in humans, ranging from an acute self-limited febrile illness (dengue fever, DF) to a severe and life-threatening vascular leakage and shock (dengue hemorrhagic fever/dengue shock syndrome, DHF/DSS) [2, 3]. In the last decade, due to a decline of vector control efforts, DENV has reemerged in tropical areas and is considered as the most common arthropod-borne tropical disease that endangers an estimated 2.5 billion people $[4,5]$. Every year, 50 million infections occur, including 500,000 hospitalizations for DHF, mainly among children, with a case fatality rate exceeding $5 \%$ in some areas. At present, diagnosis is largely clinical, treatment is supportive through hydration, and disease control is limited by eradication of the mosquito. Many efforts have been made in the search for a suitable vaccine, but the lack of an animal model and the need for a high immunogenicity vaccine against all four serotypes and a low reactogenicity are posing huge challenges in the dengue vaccine development $[6,7]$. As there is no vaccine available, the search for antiviral products is imperative. Antivirals previously designed against flaviviruses have principally focused on inhibition of viral RNA replication. Ribavirin [8], mycophenolic acid [9], and adenosine analogues [10] are believed to act as inhibitors of the RNA-dependent RNA polymerase. Due to low efficacy of these types of compounds $[9,11,12]$, more tolerable, highly potent DENV inhibitors are urgently needed. In the past few years, progression has been made in unraveling the host cell pathways upon DENV infection. It is proposed that viral epitopes on the surface of DENV can trigger cellular immune responses and subsequently the development of a severe disease. Therefore, these epitopes are potential targets for the development of a new class of antiviral products, DENV entry inhibitors. Inhibition of DENV attachment and entry into the host cell can inhibit immune activation. The cellular immune response is believed to play an important role in antibody-dependent enhancement (ADE). This is a phenomenon where crossreacting nonneutralizing antibodies generated to the first DENV infection will recognize a heterologous DENV during a secondary infection with another serotype. The DENV-Ab 


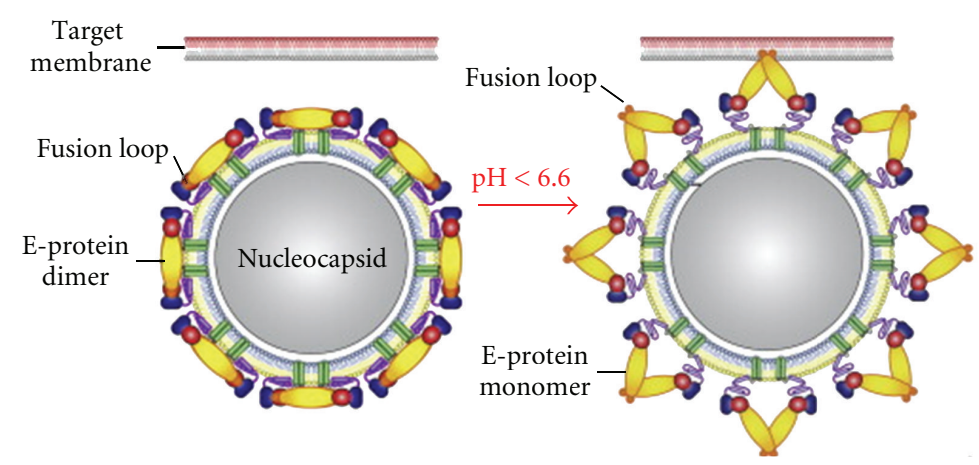

(a)

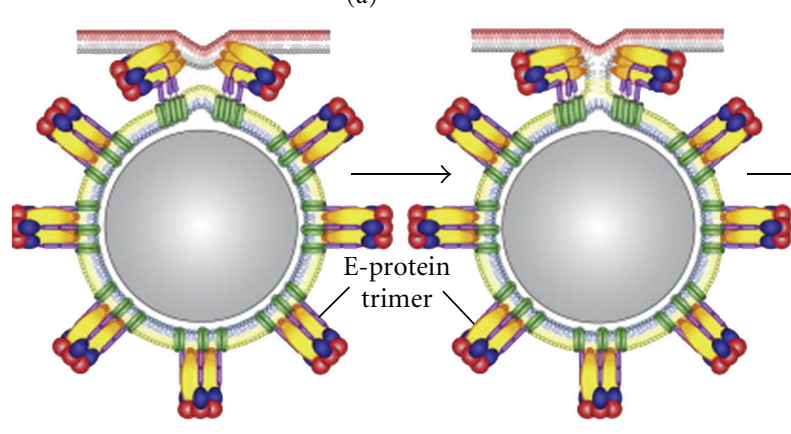

(c)

(d)

(b)

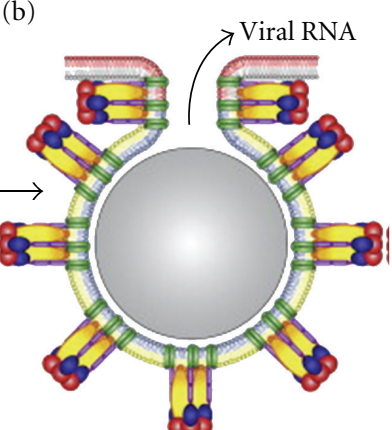

(e)

$\begin{array}{ll}\text { Domain I } & \text { Fusion loop } \\ \text { Domain II } & \text { Stem region } \\ \text { Domain III } & \text { Transmembrane helices }\end{array}$

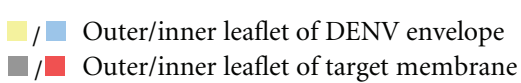

/ Outer/inner leaflet of target membrane

FIGURE 1: Schematic overview of the DENV membrane fusion process (modified figure from Stiasny et al., Amino Acids, 2009 [25]). (a) Prefusion conformation of the E-protein consists of homodimers on the virus surface. (b) Low endosomal pH triggers dissociation of the Edimers into monomers which leads to the insertion of the fusion peptide with the endosomal target membrane. (c) A stable E-protein trimer is folded in a hairpin-like structure. (d) Hemifusion intermediate in which only the outer leaflets of viral and target cellular membranes have fused. (e) Formation of the postfusion E-trimer and opening of the fusion pore allow the release of the viral RNA into the cytoplasm.

complex enhances DENV access to Fc-receptor bearing cells $[13,14]$. This results in the proliferation of $\mathrm{T}$ cells and the production of proinflammatory cytokines that have an indirect effect on the vascular endothelial cells leading to plasma leakage and DHF $[3,4,15]$.

This paper will focus on the entry process of DENV and on all identified cellular DENV receptors. A better understanding of the role of the structural envelope protein would aid the research and development of entry inhibitors against flaviviruses. Inhibition of virus attachment is a valuable antiviral strategy because it forms the first barrier to block infection. Specific molecules preventing the interaction between the host and DENV envelope are discussed.

\section{DENV Entry}

2.1. Entry Process. The infectious entry of DENV in its target cells, mainly dendritic cells [16], monocytes, and macrophages, is mediated by the viral envelope glycoprotein E via receptor-mediated endocytosis [17]. The E-protein is the major component $(53 \mathrm{kDa})$ of the virion surface and is arranged as 90 homodimers in mature virions [18]. Recent reports demonstrated that DENV enters its host cell via clathrin-mediated endocytosis [19, 20], comparable with other flaviviruses $[21,22]$. Evidence for flavivirus entry via this pathway is based on the use of inhibitors of clathrinmediated uptake, such as chlorpromazine. However, DENV entry via a nonclassical endocytic pathway independent from clathrin has also been described [23]. It seems that the entry pathway chosen by DENV is highly dependent on the cell type and viral strain. In case of the classical endocytic pathway, there is an uptake of the receptor-bound virus by clathrin-coated vesicles. These vesicles fuse with early endosomes to deliver their cargo into the cytoplasm. The Eprotein responds to the reduced $\mathrm{pH}$ of the endosome with a large conformational rearrangement $[24,25]$. The low $\mathrm{pH}$ triggers dissociation of the E-homodimer, which then leads to the insertion of the fusion peptide into the target cell membrane forming a bridge between the virus and the host. Next, a stable trimer of the E-protein is folded into a hairpin-like structure and forces the target membrane to bend towards the viral membrane, and eventually fusion takes place $[24,26,27]$. The fusion results in the release of viral RNA into the cytoplasm for initiation of replication and translation (Figure 1). 
TABLE 1: Susceptible cell types for DENV infection and putative DENV receptors.

\begin{tabular}{|c|c|c|c|c|}
\hline Species & Cell type & Cell description & DENV receptor(s) & References \\
\hline \multirow[t]{3}{*}{ Monkey } & Vero & Kidney epithelium cells & Heparan sulfate (HS) & {$[28,29]$} \\
\hline & & & Glycoprotein $(74$ kDa) & {$[30]$} \\
\hline & LLC-MK2 & Kidney cells & Glycosphingolipid & {$[31]$} \\
\hline \multirow[t]{9}{*}{ Human } & Monocytes & Primary myeloid cells & CD14/LPS & {$[32]$} \\
\hline & & & HSP70/HSP90 & {$[33]$} \\
\hline & & & Fc-receptor & {$[13,14,17]$} \\
\hline & Dendritic cells & Primary myeloid cells & DC-SIGN & {$[34,35]$} \\
\hline & Macrophages & Primary myeloid cells & Mannose receptor & {$[36]$} \\
\hline & & & CLEC5A & [37] \\
\hline & Huh & Hepatocytes & HS & {$[38,39]$} \\
\hline & HepG2 & Hepatocytes & Laminin receptor, GRP78, HS & {$[40,41]$} \\
\hline & HMEC-1 & Dermal endothelium & $\beta 3$ integrin & {$[42]$} \\
\hline \multirow[t]{3}{*}{ Hamster } & $\mathrm{BHK}$ & Kidney fibroblast cells & HS & {$[43]$} \\
\hline & & & Glycosphingolipid & {$[44]$} \\
\hline & $\mathrm{CHO}$ & Ovary cells & HS & {$[28,29]$} \\
\hline \multirow[t]{5}{*}{ Insect } & $\mathrm{C} 6 / 36$ & A. albopictus larvae cells & Laminin receptor $(37 / 67 \mathrm{kDa})$ & {$[45]$} \\
\hline & & & HSP related $(45 \mathrm{kDa})$ & {$[46,47]$} \\
\hline & & & Prohibitin $(35 \mathrm{kDa})$ & {$[48]$} \\
\hline & CCL-125 & A. Aegypti larvae cells & Prohibitin $(35 \mathrm{kDa})$ & {$[48]$} \\
\hline & AP-61 & A. pseudoscutellaris larvae cells & Glycosphingolipid & {$[31]$} \\
\hline
\end{tabular}

2.1.1. Human Cell DENV Attachment and Receptors. Prior to fusion, DENV needs to attach to specific cellular receptors. Because DENV can infect a variety of different cell types isolated from different hosts (human, insect, monkey, and even hamster), the virus must interact with a wide variety of cellular receptors. In the last decade, several candidate attachment factor/receptors are identified (Table 1).

(1) Immune Cells (Monocytes, Dendritic Cells, and Macrophages). Since 1977, monocytes are considered to be permissive for DENV infection [70]. More recent, phenotyping of peripheral blood mononuclear cells (PBMCs) from pediatric DF and DHF cases resulted in the identification of monocytes as DENV target cells [71]. First, it was believed that monocytes are important during secondary DENV infections during the ADE process, because of their Fc-receptor expression. The complex formed between the nonneutralizing antibody and the virus can bind to Fc-receptors and enhance infection in neighbouring susceptible cells $[13,14,17]$. There is evidence for the expression of a trypsin-sensitive receptor on monocytes facilitating DENV infection [72]. Later, it was shown that DENV can enter monocytes in a CD14dependent manner, because lipopolysaccharide (LPS) can inhibit the infection [32]. After LPS binding, heat shock protein (HSP) 70 and HSP90 are clustered around CD14, preventing them from interacting with DENV [33]. This indicates that HSP70 and HSP90 are part of a receptor complex in monocytes.

More detailed observation of the natural DENV infection changes the idea of monocytes being the first target cells.
Following intradermal injection of DENV-2 in mice, representing the bite of an infected mosquito, DENV occurs to replicate in the skin [73]. The primary DENV target cells in the skin are believed to be immature dendritic cells (DCs) or Langerhans cells [16, 74-76]. Immature DCs are very efficient in capturing pathogens whereas mature DCs are relatively resistant to infection. The search for cellular receptors responsible for DENV capture leads to the identification of cell-surface C-type lectin DC-specific intercellular adhesion molecule 3-grabbing nonintegrin (DC-SIGN; CD209) [34, $35,61,77]$. DC-SIGN, mainly expressed by immature DC as a tetramer, is a member of the calcium-dependent C-type lectin family and is composed out of four domains: a cytoplasmic domain responsible for signaling and internalization due to the presence of a dileucine motif, a transmembrane domain, seven to eight extracellular neck repeats implicated in the oligomerization of DC-SIGN, and a carbohydrate recognition domain (CRD) (Figure 2) [78]. The CRD recognizes high-mannose $\mathrm{N}$-glycans and fucose-containing blood group antigens $[79,80]$. Importantly, DC-SIGN can bind a variety of pathogens like human immunodeficiency virus (HIV) [81], hepatitis C virus (HCV) [82], Ebola virus [83], and several bacteria, parasites, and yeasts [84]. Many of these pathogens have developed strategies to manipulate DCSIGN signaling to escape from an immune response [84]. Following antigen capture in the periphery, DCs maturate by upregulation of the costimulatory molecules and migrate to secondary lymphoid organs. Activated DCs are stimulators of naive $\mathrm{T}$ cells and they initiate production of cytokines and chemokines [85]. Inhibition of the initial interaction 
TABLE 2: Overview of all described DENV entry inhibitors.

\begin{tabular}{|c|c|c|c|c|}
\hline Class & Compound & Serotype* & Cell line & References \\
\hline \multirow[t]{6}{*}{ Fusion inhibitors } & 1OAN1 & DENV-2 & LLC-MK2 & [49] \\
\hline & DN59 & DENV-2 & LLC-MK2 & {$[50]$} \\
\hline & Compound 6 & DENV-1-4 & A549, BHK & {$[51]$} \\
\hline & Tetracycline derivates & DENV-2 & BHK & {$[52]$} \\
\hline & Doxorubicin derivate & DENV-1, $-2,-3$ & Vero, C6/36 & {$[53]$} \\
\hline & NITD448 & DENV-2 & BHK, C6/36 & {$[54]$} \\
\hline \multirow[t]{7}{*}{ Glycosidase inhibitors } & Castanospermine & DENV-1-4 & BHK & {$[55,56]$} \\
\hline & & DENV-2 & Huh-7 & {$[55]$} \\
\hline & DNJ & DENV-1 & Mouse neuro 2a cells & {$[56]$} \\
\hline & NN-DNJ & DENV-2 & $\mathrm{BHK}$ & {$[57]$} \\
\hline & Alkylated iminocyclitol & DENV-2 & $\mathrm{BHK}$ & {$[58]$} \\
\hline & OSL-9511 & DENV-2 & BHK & {$[59]$} \\
\hline & CM-9-78 & DENV-2 & BHK & {$[60]$} \\
\hline \multirow[t]{5}{*}{$\overline{C B A s}$} & Con A, WGA & DENV-2 & BHK & {$[43]$} \\
\hline & HHA, GNA, UDA & DENV-1-4 & Raji/DC-SIGN, MDDC & {$[61,62]$} \\
\hline & & DENV-1-4 & Huh-7, U87/DC-SIGN & Unpublished results \\
\hline & & DENV-1-4 & Raji/L-SIGN, U87/L-SIGN & Unpublished results \\
\hline & PRM-S & DENV-2 & MDDC & {$[62]$} \\
\hline \multirow[t]{15}{*}{ Heparan mimetics } & GAG & DENV-2 & Vero & {$[28]$} \\
\hline & Heparin & DENV-2 & Vero & {$[28,29]$} \\
\hline & & DENV-2 & BHK & {$[43]$} \\
\hline & & DENV-2 & Hepatocytes & {$[38]$} \\
\hline & Suramin & DENV-2 & Vero, BHK & {$[28,63]$} \\
\hline & PI-88 & DENV-2 & $\mathrm{BHK}$ and in mice & {$[63]$} \\
\hline & PPS & DENV-2 & $\mathrm{BHK}$ & {$[63]$} \\
\hline & Fucoidan & DENV-2 & BHK & {$[64]$} \\
\hline & Sulfated galactomannan & DENV-1 & $\mathrm{C} 6 / 36$ & {$[65]$} \\
\hline & DL-galactan & DENV-2, -3 & Vero, HepG2 & {$[66]$} \\
\hline & Carrageenan & DENV-2, -3 & Vero, HepG2 & {$[66,67]$} \\
\hline & $\alpha$-D-glucan & DENV-2 & $\mathrm{BHK}$ & {$[68]$} \\
\hline & Dextran sulfate 8000 & DENV-2 & Hepatocytes, Vero & {$[66]$} \\
\hline & DS $(\mathrm{MW}>500,000 \mathrm{Da})$ & DENV-2 & Raji/DC-SIGN & {$[61]$} \\
\hline & Zosteric acid & DENV-1-4 & LLC-MK2 & {$[69]$} \\
\hline
\end{tabular}

* Serotype: The serotype mentioned is the serotype that has been tested and found susceptible to inhibition by the compound. Non-mentioned serotypes were not tested or could not be inhibited by the compound.

between DENV and DC could prevent an immune response. DC-SIGN could be a target for antiviral therapy by interrupting the viral entry process.

Besides DC, macrophages play a key role in the immunopathogenesis of DENV infection as a source of immunomodulatory cytokines [86]. Recently, Miller et al. showed that the mannose receptor (MR; CD206) mediates DENV infection in macrophages by recognition of the glycoproteins on the viral envelope [36]. MR is also present on monocyte-derived DC (MDDC), and anti-MR antibodies can inhibit DENV infection, although to a lesser extent than anti-DC-SIGN antibodies do [62]. MR differs from DC-SIGN in ligand specificity and acts as an internalization receptor for DENV instead of an attachment factor. Another C-type lectin,
CLEC5A (C-type lectin domain family 5, member A) expressed by human macrophages can also interact with DENV and acts as a signaling receptor for the release of proinflammatory cytokines [37]. However, whereas the DC-SIGNDENV interaction is calcium-dependent, CLEC5A binding to its ligand is not dependent on calcium. Mannan and fucose can inhibit the interaction between CLEC5A and DENV, indicating that the interaction is carbohydrate-dependent [37]. However, a glycan array demonstrated that there is no binding signal between CLEC5A and N-glycans of mammals or insects [87]. The molecular interaction between CLEC5A and DENV remains to be elucidated.

Immune cells, in particular dendritic cells, are the most relevant cells to use in the discovery of antiviral drugs against 


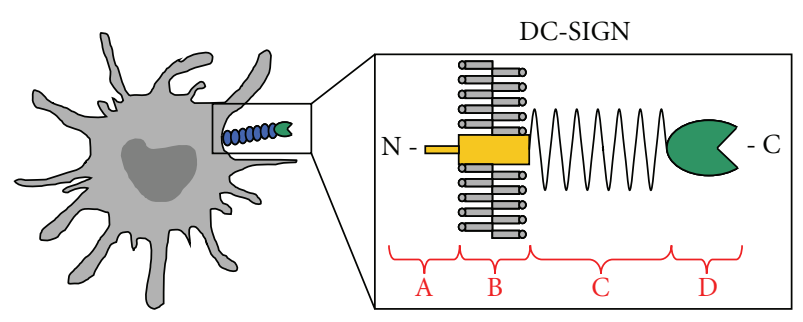

Figure 2: Structure of DC-SIGN. DC-SIGN, mainly expressed by human dendritic cells in the skin, is composed out of four domains: (A) cytoplasmic domain containing internalization signals, (B) transmembrane domain, (C) 7 or 8 extracellular neck repeats implicated in the oligomerization of DC-SIGN, and (D) carbohydrate recognition domain which can interact calcium-dependently with a variety of pathogens.

dengue virus, but the isolation of these cells and the characterization is labour intensive and time consuming.

(2) Liver Cells. The liver is an important target organ of dengue, in particular in DHF and DSS, because liver enzymes are usually elevated [88] and apoptosis of hepatocytes has been reported [89]. The interaction of DENV with liver cells has been studied.

Heparan sulfate (HS), the most ubiquitous member of the glycosaminoglycan (GAG) family, present on human hepatocytes, is described as a putative receptor for DENV $[28,29,38,43]$. HS is also expressed by Vero cells, CHO cells, and BHK cells which are widely used in the study of dengue virus infection because of the easy cell growth conditions. HS very often acts as an attachment factor to concentrate the virus on the cell surface to facilitate binding to a second receptor. However, the contribution of HS to internalize DENV appears to vary in a serotype-specific manner [39, 90]. In Vero cells, a putative glycoprotein coreceptor is characterized of $74 \mathrm{kDa}$ binding DENV-4 in a carbohydratedependent manner [30]. Another carbohydrate molecule characterized to interact with all four serotypes of DENV in $\mathrm{BHK}$ cells and insect cells is the terminal disaccharide of a glycosphingolipid, neolactotetraosylceramide [31, 44].

Besides HS [38, 39], glucose-regulated protein 78 (GRP78) is identified as a possible liver receptor in hepatocytes [40]. Wati et al. showed that GRP78 is also upregulated in DENV-infected monocytes and acts as a chaperone for viral-protein production during DENV infection [91]. Liver cells are important target cells during dengue virus infection, and the liver cell line Huh-7 has easy growth conditions. In general, liver cells are not widely used for studying dengue virus infection, but liver cells have more clinical relevance in contrast to monkey cells (Vero) or hamster cells (BHK) and should get more attention to use in screening discovery programs for antiviral drugs.

(3) Endothelial Cells. Liver/lymph node-specific ICAM-3 grabbing nonintegrin (L-SIGN) is a DC-SIGN-related transmembrane C-type lectin expressed on endothelial cells in liver, lymph nodes, and placenta $[92,93]$. Similar to DCSIGN, L-SIGN is a calcium-dependent carbohydrate-binding protein and can interact with HIV [92], HCV [82], Ebola virus [83], West Nile virus [94], and DENV [35]. Although endothelial cells [95] and liver endothelial cells [89] are permissive for DENV and L-SIGN-expression makes unsusceptible cells susceptible for DENV infection, the in vivo role for L-SIGN in DENV entry remains to be established. Upregulation of $\beta 3$ integrin has been observed following DENV infection in human endothelial cells [42], and DENV entry is highly dependent on the expression of $\beta 3$ integrin. This indicates that $\beta 3$ integrin can act as an important secondary receptor for DENV entry in endothelial cells.

\subsubsection{Mosquito Cell DENV Attachment and Receptors. DENV} entry into mosquito cells is poorly understood. Previously, electron microscopic studies in the Aedes Albopictus mosquito cell line, C6/36, have shown that DENV penetrates directly into the cytoplasm by fusion at the plasma membrane [96]. In contrast, experiments concentrating on cell fusion of mosquito cells and virus inhibition with acidotropic agents have provided evidence of viral uptake through receptormediated endocytosis [97]. Recently, according to overlay protein-binding assays, two surface proteins on C6/36 cells with molecular masses 80 en $67 \mathrm{kDa}$ have been demonstrated to interact with all four serotypes of DENV [98]. This is in contrast with other reports, where a surface protein of $45 \mathrm{kDa}$ was identified as a receptor for DENV-4 in C6/36 cells [46] which was later designated as a heat-shockrelated protein (HSP related) [47]. Also, the $37 / 67 \mathrm{kDa}$ protein was identified as the laminin receptor expressed by C6/36 cells and hepatocytes $[41,45]$. However, the binding capacity of DENV to interact with the laminin receptor is serotype-specific (only DENV-3 and DENV-4) and cell-typedependent (only detected in larvae cells and not in adult mosquito cells). Recently, prohibitin is characterized as a DENV-2 receptor in insect cells [48]. However, it is unclear if this conserved eukaryotic protein plays a role in DENV infection in mammalian cells.

\section{The DENV Envelope}

The DENV E-protein induces protective immunity, and flavivirus serological classification is based on its antigenic variation. During replication, the virion assumes three conformational states: the immature, mature, and fusion-activated form. In the immature state, the E-protein is arranged as a heterodimer and generates a "spiky" surface because the premembrane protein ( $\mathrm{prM}$ ) covers the fusion peptide. In the Golgi apparatus, the virion maturates after a rearrangement of the E-protein. The E-heterodimer transforms to an E-homodimer and results in a "smooth" virion surface. After a furin cleavage of the prM to pr and $M$, the virion is fully maturated and can be released from the host cell. Upon fusion, the low endosomal $\mathrm{pH}$ triggers the rearrangement of the E-homodimer into a trimer [99].

The E-protein monomer is composed out of $\beta$-barrels organized in three structural domains (Figure 3). The central 


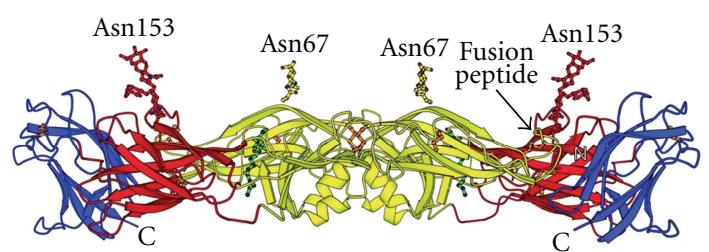

Figure 3: Location of the $2 \mathrm{~N}$-glycans on the envelope protein of DENV. The DENV E-protein dimer carries $2 \mathrm{~N}$-glycans on each monomer at Asn67 and Asn153. $\beta$-strands are shown as ribbons with arrows, $\alpha$-helices are shown as coiled ribbons. Thin tubes represent connecting loops. Domain I is shown is red, domain II is shown in yellow and contains the fusion peptide near Asn153. Domain III is shown in blue. Disulfide bridges are shown in orange. In green, the ligand N-octyl-D-glucoside is shown, which interacts with the hydrophobic pocket between domains I and II (modified figure from Modis et al., PNAS, 2003) [100].

domain I contains the aminoterminus and contains two disulphide bridges. Domain II is an extended finger-like domain that bears the fusion peptide and stabilizes the dimer. This sequence contains three disulphide bridges and is rich in glycine. Between domain I and domain II is a binding pocket that can interact with a hydrophobic ligand, the detergent $\beta$-N-octyl-glucoside. This pocket is an important target for antiviral therapy because mutations in this region can alter virulence and the $\mathrm{pH}$ necessary for the induction of conformational changes. The immunoglobulin-like domain III contains the receptor-binding motif, the C-terminal domain, and one disulphide bond [100, 101]. Monoclonal antibodies recognizing domain III are the most efficient of blocking DENV [102,103] and this domain is therefore an interesting target for antiviral therapy.

Because DC-SIGN is identified as a receptor for DENV in primary DC in the skin and DC-SIGN recognizes highmannose sugars, carbohydrates present on the E-protein of DENV could be important for viral attachment. The E-protein has two potential glycosylation sites: Asn67 and Asn153. Glycosylation at Asn153 is conserved in flaviviruses, with the exception of Kunjin virus [104] and is located near the fusion peptide in domain II [100, 101] (Figure 3). Glycosylation at Asn67 is unique for DENV [101]. The glycosylation at Asn67 is demonstrated to be essential for infection of MDDC, indicating an interaction between DC-SIGN and the glycan at Asn67 [105, 106]. Generally, the function of glycosylation of surface proteins is proper folding of the protein, trafficking in the endoplasmic reticulum, interaction with receptors, and influencing virus immunogenicity [107].

There are some contradictions in terms of necessity of glycosylation of Asn67 and Asn153 during DENV viral progeny. Johnson et al. postulated that DENV-1 and DENV-3 have both sites glycosylated and that DENV-2 and DENV4 have only one $\mathrm{N}$-glycan at Asn-67 [108]. In contrast, a study comparing the number of glycans in multiple isolates of DENV belonging to all four serotypes led to the consensus that all DENV strains have two N-glycans on the E-protein [109]. Nevertheless, mutant DENV lacking the glycosylation at Asn153 can replicate in mammalian and insect cells, indicating that this glycosylation is not essential for viral replication $[105,110]$. However, there is a change in phenotype because ablation of glycosylation at Asn153 in DENV is associated with the induction of smaller plaques in comparison to the wild type virus [105]. Asn153 is proximal to the fusion peptide, and therefore deglycosylation at Asn153 showed also an altered $\mathrm{pH}$-dependent fusion activity and displays a lower stability $[111,112]$.

DENV lacking the glycosylation at Asn67 results in a replication-defective phenotype, because this virus infects mammalian cells weakly and there is a reduced secretion of DENV E-protein. Replication in mosquito cells was not affected, because the mosquito cells restore the N-glycosylation at Asn67 with a compensatory site-mutation (K64N) generating a new glycosylation site $[105,113]$. These data are in contrast with other published results, where was demonstrated that DENV lacking the Asn67-linked glycosylation can grow efficiently in mammalian cells, depending on the viral strain and the amino acid substitution abolishing the glycosylation process [110]. A compensatory mutation was detected (N124S) to repair the growth defect without creating a new glycosylation site. Thus, the glycan at Asn67 is not necessary for virus growth, but a critical role for this glycan in virion release from mosquito cells was demonstrated [110].

Virions produced in the mosquito vector and human host may have structurally different N-linked glycans, because the glycosylation patterns are fundamentally different $[109,114]$. N-glycosylation in mammalian cells is often of the complex type because a lot of different processing enzymes could add a diversity of monosaccharides. Glycans produced in insect cells are far less complex, because of less diversity in processing enzymes, and usually contain more high-mannose and pauci-mannose-type glycans. DC-SIGN can distinguish between mosquito and mammalian cellderived alphavirus [115] and West Nile virus [94], resulting in a more efficient infection by a mosquito-derived virus, but this was not the case for DENV [109].

\section{DENV Entry Inhibitors}

4.1. Fusion Inhibitors. By docking experiments and physicochemical algorithms using the structural data of the Eprotein, small molecules and peptides targeting the hydrophobic pocket are characterized as entry inhibitors of DENV (Table 2) [49-51]. Nicholson et al. showed that two peptide entry inhibitors, DN59 and 1OAN1, could inhibit ADE in vitro, indicating that entry inhibitors could prevent development of the more severe disease outcome of dengue, DHF/DSS [116]. Tetracycline derivates have been shown to interact with the hydrophobic pocket of the E-protein (Figure 3) and, due to steric hindrance, prevent conformational rearrangements of the E-protein and subsequently prevent viral fusion [52]. A derivate of the antibiotic doxorubicin, SA-17, has a structure partially similar to tetracycline. SA-17 has been demonstrated to have antiviral activity against DENV serotype 1, 2, and 3 in Vero and C6/36 cells and interferes with viral entry by binding to the hydrophobic pocket of the E-protein without being virucidal [53]. 
Recently, two fusion assays using C6/36 cells have been optimized to examine the antifusion activities of a variety of compounds. NITD448, selected in docking experiments, was demonstrated to inhibit DENV-2 fusion by binding to the hydrophobic pocket of the E-protein [54]. All these compounds can serve as lead compounds for further drug discovery and for further elucidation of the entry process of DENV.

4.2. Glycosidase Inhibitors. Because of the risk of ADE, it is very important to achieve maximal protection to the same extent against all four serotypes with one drug or vaccine. Inhibitors targeting host cell processes, as glycosylation processes, are interesting targets and could overcome this problem. We will further focus on some $\alpha$-glycosidase inhibitors that affect the modification of N-glycosylation of the viral proteins in the endoplasmic reticulum (ER).

The two lead compounds in inhibiting glycoprotein folding are imino sugars deoxynojirimycin (DNJ) and castanospermine (CSP) which mimic glucose (reviewed in [117]). CSP is a natural alkaloid derived from the black bean and is water soluble. CSP inhibits all four DENV serotypes by reducing the number of secreted particles, due to inappropriate glycoprotein folding, and by decreasing the infectivity of the secreted DENV particles $[55,56]$. DNJ exerts the same mechanism of action as castanospermine [56]. Because of the low efficacy and cytotoxic effects, the development of imino sugars is limited. Alkylated iminocyclitol derivates, containing an imino sugar head group and an $\mathrm{N}$-alkyl side chain, proved to be more potent against DENV-2 and less cytotoxic than DNJ [58]. N-alkylated derivates of DNJ (N-nonyl-DNJ $(\mathrm{NN}-\mathrm{DNJ}))$ have been shown to have increased antiviral potency compared to DNJ, but cytotoxic effects were also increased $[57,118]$. However, NN-DNJ and a CSP derivate both reduced significantly viremia in a dengue fever mouse model [119]. Further optimization of the chemical structure of the imino sugar DNJ leads to the production of N-pentyl(1-hydroxycyclohexyl)-DNJ (OSL-9511), an iminocyclitol with a DNJ head group, which showed reduced cytotoxicity and retained antiviral activity against DENV [59]. To improve the antiviral efficacy, a hydroxyl group was removed and an oxygen atom was added. This resulted in a new compound, CM-9-78, with exerted high anti-DENV activity and very low cytotoxicity [60]. Recently, the compound CM9-78 and another variant CM-10-78 were tested in vivo and were shown to reduce viremia modestly by 2 -fold. To improve the antiviral efficacy in vivo, a combination therapy was tested with ribavirin, a compound with a different antiviral mechanism of action. Whereas ribavirin by itself did not reduce viremia [119], combination of CM-10-78 and ribavirin demonstrated a clear enhancement in the reduction of viremia [120].

To conclude, there is a limited use of glycosidase inhibitors because of their toxicity and low specificity, but these compounds indeed help to understand the process of the E-protein glycosylation. In the last decade, not much progression has been made in the development of inhibitors targeting host glycosidase enzymes by biochemical modifications, but combination with other classes of inhibitors seems to achieve the best antiviral efficacy.
4.3. Carbohydrate-Binding Agents (CBAs). The CBAs form a large group of natural proteins, and they can be isolated from different organisms. Concanavalin A, isolated from the Jack bean, binds to mannose residues and wheat germ agglutinin (WGA) binds to $\mathrm{N}$-acetylglucosamine (Glc-NAc) residues. Both compounds can reduce DENV induced plaque formation in BHK cells [43]. A competition assay, using mannose, proved that the inhibitory effect of Con A was due to binding $\alpha$-mannose residues on the viral protein, because mannose successfully competed with Con A [43]. Recently, three plant lectins, Hippeastrum hybrid (HHA), Galanthus nivalis (GNA), and Urtica dioica (UDA), isolated from the amaryllis, snowdrop, and stinging nettle, respectively, have been shown to inhibit DENV-2 infection in Raji/DC-SIGN cells [61]. Binding studies revealed that the CBAs act during the adsorption phase of the virus to the host cell. HHA and GNA have been shown to interact with mannose-residues [121, 122], and UDA can recognize specifically Glc-NAc residues [123]. Mannose and Glc-NAc molecules are present in the backbone of the high-mannose type glycans on the viral envelope protein. Because DC-SIGN can also recognize these sugar molecules, the interaction between DC-SIGN and DENV E-glycoprotein is disrupted by HHA, GNA, and UDA. DC-SIGN, present on DC in the skin [16], is important during the first steps of a natural infection and thus forms an important target to focus on. The antiviral activity profile of the CBAs has been extended using different cell types. Recently, the antiviral activity of HHA, GNA, and UDA has been demonstrated in primary MDDC against all four DENV serotypes, and, importantly, the potency of the three CBAs was much higher in MDDC than in DC-SIGN transfected cell lines, such as Raji/DC-SIGN [62]. Raji cells and U87 cells transfected with L-SIGN, a DC-SIGN-related receptor, can be infected with DENV and this infection can also be inhibited with the three plant lectins (Figure 4 and unpublished data). However, since plant lectins are expensive to isolate in large quantities and not orally bioavailable, the search for nonpeptidic small molecules is necessary. PRM$\mathrm{S}$ is a highly soluble nonpeptidic small-size carbohydratebinding antibiotic and proved to inhibit DENV-2 in MDDC [62]. These data indicate that targeting the initial interaction between the N-glycans on the DENV envelope and the host cell is promising and that the CBAs have broad spectrum antiviral activity.

4.4. Heparan Mimetics. Because HS is a putative receptor for DENV, it is interesting to target the E-protein-HS interaction with soluble GAGs and other highly charged polyanions mimicking HS to prevent DENV entry (Table 2). GAG and heparin, a more highly sulfated protein than HS, can prevent binding of DENV to Vero cells and BHK cells [28]. Domain III of the E-protein is responsible for the interaction with HS [124]. It has been widely assumed that domain III is conserved within each DENV serotype and it is a good target for vaccines, because it contains epitopes recognized by neutralizing antibodies $[102,103]$.

The pharmaceutical product suramin, a small polyanion mimicking the structure of HS, and persulfated GAGs can bind to the polyanion-binding site of the DENV E-protein 

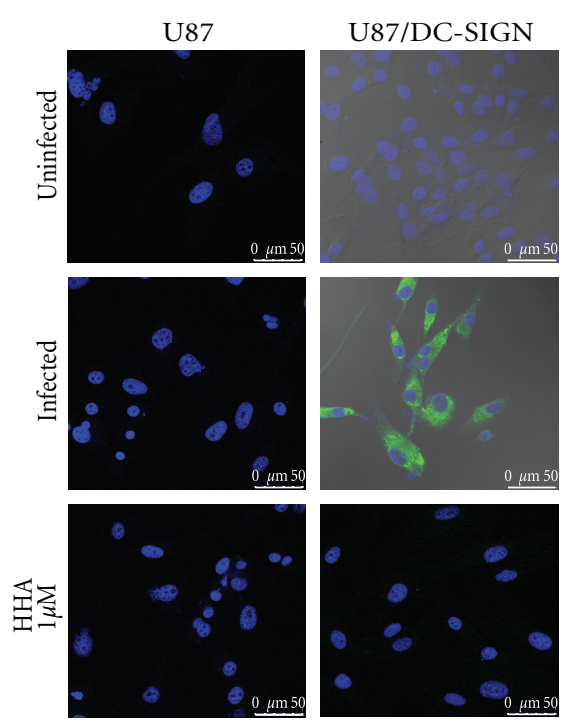

(a)
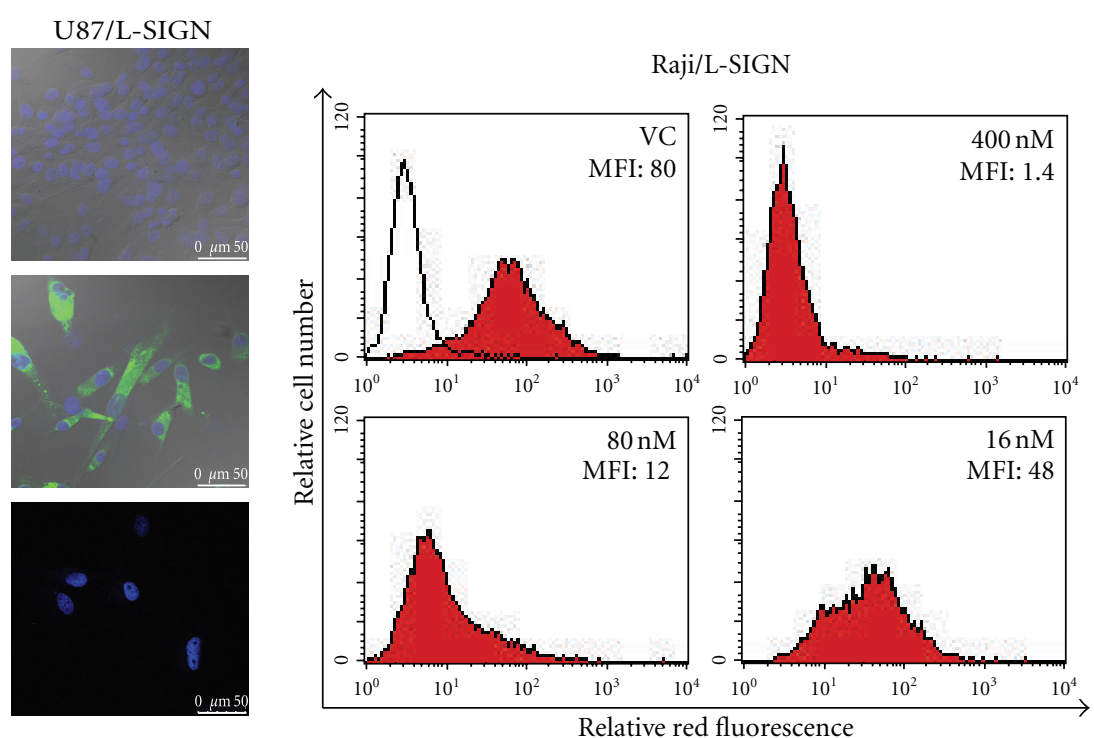

(b)

FIGURE 4: Antiviral activity of HHA in DC-SIGN and L-SIGN transfected cell lines. (a) U87, U87/DC-SIGN, and U87/L-SIGN cells were infected with DENV-2 in the presence or absence of HHA. DENV-2 infection was analyzed by confocal microscopy using specific DENV antibodies as previously described [62]. The cell nucleus is shown in blue (Dapi) and DENV-2 infected cells are shown in green (anti-DENV $\mathrm{Ab}+$ Alexa 488). (b) Raji/L-SIGN cells were infected with DENV-2 in the presence or absence of HHA, and viral infection was analyzed by flow cytometry using specific DENV antibodies. The open histogram represents uninfected cells. The upper left red histogram shows the virus control (VC), and the mean fluorescence of intensity (MFI) is indicated in each panel. HHA was added at different concentrations (400-80-16 nM), and the MFI shows the dose-dependent inhibition of the DENV-2 infection in Raji/L-SIGN cells. Comparable antiviral activity of HHA in Raji/DC-SIGN cells was obtained [61].

[125] and can inhibit DENV infection. Pentosan polysulfate (PPS) and the sulfated polysaccharide PI-88, which are currently in clinical trials for antitumor activity, inhibit DENV-2 infection in BHK cells. In IFN- $\alpha / \gamma$ receptor knockout mice, a mouse model for DENV, PI- 88 demonstrated an increase in survival time [63] whereas suramin and PPS did not show a beneficial effect in vivo.

Fucoidan, a sulfated polysaccharide isolated from marine alga, has specifically antiviral activity against DENV-2 in BHK cells and not against the other serotypes [64]. This is in agreement with others, where was demonstrated that sulfated polysaccharides from red seaweeds, carrageenan, and DLgalactan had antiviral activity against DENV-2 and DENV3 but a very weak and no antiviral activity against DENV-4 and DENV-1, respectively, in human hepatocytes and Vero cells. The polysaccharides were not inhibitory in mosquito cells. Together with the fact that sulfated galactomannans are proved to be inhibitors of DENV-1 in C6/36 cells [65], these data indicate that the antiviral activity of sulfated polysaccharides is serotype- and cell-type-dependent [66].

Heparin analogues often have anticoagulant activities and this forms a major restriction factor for their use as antiviral product. Thus the search for polysaccharides with fewer side effects is imperative. DL-galactan from red seaweed lacks cytotoxic effects and anticoagulant properties and exhibits a high antiviral activity against DENV-2 [126]. Next, two $\alpha$-D-glucans were isolated from a widely used Chinese herb with several therapeutic activities. These two polysaccharides exhibit anti-DENV-2 activity in BHK cells and sulfated derivates of one of the compounds proved even to be more potent [68]. This is in accordance with previous findings demonstrating that the antiviral activity of polysaccharides increases with molecular weight and degree of sulfation $[28,125]$.

There are some contrasting data concerning the antiviral activity of dextran sulfate. Dextran sulfate with molecular weight $8000 \mathrm{Da}$ (DS8000) has been shown to have antiviral activity against DENV-2 in human hepatocytes and Vero cells [66]. This is in contrast with our data, where DS5000 had no antiviral activity against DENV-2 in Raji/DC-SIGN cells and Vero cells [61]. High molecular weight DS (MW = $500,000 \mathrm{Da})$ had no antiviral activity against DENV in Vero cells $[28,61]$, but recently this compound had been shown to inhibit DENV-2 in human Raji/DC-SIGN cells [61]. These data reinforce the idea that the entry process and thereby the antiviral activity of sulfated polyanions is cell-type- and serotype-dependent.

Another sulfated compound is the antiadhesive compound p-sulfoxy-cinnamic acid, zosteric acid, derived from a marine eelgrass. It showed to be nontoxic and inhibitory against all four serotypes in LLC-MK2 cells [69]. It has been shown that this compound promotes inappropriate viruscell attachment and prevents virus entry.

In general, binding studies revealed that polysaccharides act during virus adsorption and internalization [66, 127]. The mechanism of action of carrageenan is by inhibition 
of a postadsorption process, namely, the release of the viral nucleocapsid into the cytoplasm, probably due to the interaction with the E-protein [67]. The antiviral effect of HS mimetics is probably due to steric hindrance and the negative charged sulfate groups, but there is a dose-limiting effect due to their anticoagulant activity. The antiviral activity of sulfated polyanions is cell-type- and serotype-dependent and thus not suitable for further clinical testing.

\section{Conclusion}

DENV is able to infect many types of host cells and this resulted in the identification of several putative DENV receptors. DCs in the skin are believed to be the first target cells, and therefore DC-SIGN is assumed to be the most important DENV receptor until now. The unraveling of the entry process of DENV into the host cell and the recent progresses in virtual screening and docking techniques have lead to the development of a new class of DENV inhibitors, entry inhibitors. This class of compounds has great potential to be used either alone or in combination therapy with viral replication inhibitors. It has been shown that entry inhibitors can prevent ADE in human cells and subsequently immune activation [116]. This indicates a very important feature for further development of entry inhibitors and for future clinical studies.

\section{Acknowledgments}

The work of the authors was supported by the Katholieke Universiteit Leuven (GOA no. 10/014 and PF/10/018) and the FWO (no. G.485.08).

\section{References}

[1] S. B. Halstead, "Dengue virus-mosquito interactions," Annual Review of Entomology, vol. 53, pp. 273-291, 2008.

[2] T. Solomon and M. Mallewa, "Dengue and other emerging flaviviruses," Journal of Infection, vol. 42, no. 2, pp. 104-115, 2001.

[3] J. G. Rigau-Pérez, G. G. Clark, D. J. Gubler, P. Reiter, E. J. Sanders, and A. V. Vorndam, "Dengue and dengue haemorrhagic fever," Lancet, vol. 352, no. 9132, pp. 971-977, 1998.

[4] S. B. Halstead, "Dengue," Lancet, vol. 370, no. 9599, pp. 1644-1652, 2007.

[5] D. J. Gubler, "Dengue and dengue hemorrhagic fever," Clinical Microbiology Reviews, vol. 11, no. 3, pp. 480-496, 1998.

[6] S. Murrell, S. C. Wu, and M. Butler, "Review of dengue virus and the development of a vaccine," Biotechnology Advances, vol. 29, no. 2, pp. 239-247, 2011.

[7] S. S. Whitehead, J. E. Blaney, A. P. Durbin, and B. R. Murphy, "Prospects for a dengue virus vaccine," Nature Reviews Microbiology, vol. 5, no. 7, pp. 518-528, 2007.

[8] R. Takhampunya, S. Ubol, H. S. Houng, C. E. Cameron, and R. Padmanabhan, "Inhibition of dengue virus replication by mycophenolic acid and ribavirin," Journal of General Virology, vol. 87, no. 7, pp. 1947-1952, 2006.

[9] M. S. Diamond, M. Zachariah, and E. Harris, "Mycophenolic acid inhibits dengue virus infection by preventing replication of viral RNA," Virology, vol. 304, no. 2, pp. 211-221, 2002.
[10] Y. L. Chen, Z. Yin, S. B. Lakshminarayana et al., "Inhibition of dengue virus by an ester prodrug of an adenosine analog," Antimicrobial Agents and Chemotherapy, vol. 54, no. 8, pp. 3255-3261, 2010.

[11] J. M. Crance, N. Scaramozzino, A. Jouan, and D. Garin, "Interferon, ribavirin, 6-azauridine and glycyrrhizin: antiviral compounds active against pathogenic flaviviruses," Antiviral Research, vol. 58, no. 1, pp. 73-79, 2003.

[12] P. Leyssen, E. De Clercq, and J. Neyts, "Perspectives for the treatment of infections with Flaviviridae," Clinical Microbiology Reviews, vol. 13, no. 1, pp. 67-82, 2000.

[13] A. Takada and Y. Kawaoka, "Antibody-dependent enhancement of viral infection: molecular mechanisms and in vivo implications," Reviews in Medical Virology, vol. 13, no. 6, pp. 387-398, 2003.

[14] S. C. Kliks, A. Nisalak, W. E. Brandt, L. Wahl, and D. S. Burke, "Antibody-dependent enhancement of dengue virus growth in human monocytes as a risk factor for dengue hemorrhagic fever," American Journal of Tropical Medicine and Hygiene, vol. 40, no. 4, pp. 444-451, 1989.

[15] A. T. A. Mairuhu, J. Wagenaar, D. P. M. Brandjes, and E. C. M. Van Gorp, "Dengue: an arthropod-borne disease of global importance," European Journal of Clinical Microbiology and Infectious Diseases, vol. 23, no. 6, pp. 425-433, 2004.

[16] S. J. L. Wu, G. Grouard-Vogel, W. Sun et al., "Human skin Langerhans cells are targets of dengue virus infection," Nature Medicine, vol. 6, no. 7, pp. 816-820, 2000.

[17] Z. Kou, M. Quinn, H. Chen et al., "Monocytes, but not T or $B$ cells, are the principal target cells for dengue virus (DV) infection among human peripheral blood mononuclear cells," Journal of Medical Virology, vol. 80, no. 1, pp. 134-146, 2008.

[18] R. J. Kuhn, W. Zhang, M. G. Rossmann et al., "Structure of dengue virus: implications for flavivirus organization, maturation, and fusion," Cell, vol. 108, no. 5, pp. 717-725, 2002.

[19] E. G. Acosta, V. Castilla, and E. B. Damonte, "Functional entry of dengue virus into Aedes albopictus mosquito cells is dependent on clathrin-mediated endocytosis," Journal of General Virology, vol. 89, no. 2, pp. 474-484, 2008.

[20] H. M. Van Der Schaar, M. J. Rust, Chen et al., "Dissecting the cell entry pathway of dengue virus by single-particle tracking in living cells," PLoS Pathogens, vol. 4, no. 12, Article ID e1000244, 2008.

[21] J. J. H. Chu and M. L. Ng, "Infectious entry of West Nile virus occurs through a clathrin-mediated endocytic pathway," Journal of Virology, vol. 78, no. 19, pp. 10543-10555, 2004.

[22] M. Nawa, T. Takasaki, K. I. Yamada, I. Kurane, and T. Akatsuka, "Interference in Japanese encephalitis virus infection of Vero cells by a cationic amphiphilic drug, chlorpromazine," Journal of General Virology, vol. 84, no. 7, pp. 1737-1741, 2003.

[23] E. G. Acosta, V. Castilla, and E. B. Damonte, "Alternative infectious entry pathways for dengue virus serotypes into mammalian cells," Cellular Microbiology, vol. 11, no. 10, pp. 1533-1549, 2009.

[24] Y. Modis, S. Ogata, D. Clements, and S. C. Harrison, "Structure of the dengue virus envelope protein after membrane fusion," Nature, vol. 427, no. 6972, pp. 313-319, 2004.

[25] K. Stiasny, R. Fritz, K. Pangerl, and F. X. Heinz, "Molecular mechanisms of flavivirus membrane fusion," Amino Acids, vol. 41, no. 5, pp. 1159-1163, 2009.

[26] Y. Zhang, W. Zhang, S. Ogata et al., "Conformational changes of the flavivirus E glycoprotein," Structure, vol. 12, no. 9, pp. 1607-1618, 2004. 
[27] C. S. S. Martín, C. Y. Liu, and M. Kielian, "Dealing with low pH: entry and exit of alphaviruses and flaviviruses," Trends in Microbiology, vol. 17, no. 11, pp. 514-521, 2009.

[28] Y. Chen, T. Maguire, R. E. Hileman et al., "Dengue virus infectivity depends on envelope protein binding to target cell heparan sulfate," Nature Medicine, vol. 3, no. 8, pp. 866-871, 1997.

[29] R. Germi, J. M. Crance, D. Garin et al., "Heparan sulfatemediated binding of infectious dengue virus type 2 and yellow fever virus," Virology, vol. 292, no. 1, pp. 162-168, 2002.

[30] J. J. Martínez-Barragán and R. M. Del Angel, "Identification of a putative coreceptor on Vero cells that participates in dengue 4 virus infection," Journal of Virology, vol. 75, no. 17, pp. 7818-7827, 2001.

[31] S. Wichit, A. Jittmittraphap, K. I. Hidari et al., "Dengue virus type 2 recognizes the carbohydrate moiety of neutral glycosphingolipids in mammalian and mosquito cells," Microbiology and Immunology, vol. 55, no. 2, pp. 135-140, 2011.

[32] Y. C. Chen, S. Y. Wang, and C. C. King, "Bacterial lipopolysaccharide inhibits dengue virus infection of primary human monocytes/macrophages by blockade of virus entry via a CD14-dependent mechanism," Journal of Virology, vol. 73, no. 4, pp. 2650-2657, 1999.

[33] J. Reyes-Del Valle, S. Chávez-Salinas, F. Medina, and R. M. Del Angel, "Heat shock protein 90 and heat shock protein 70 are components of dengue virus receptor complex in human cells," Journal of Virology, vol. 79, no. 8, pp. 4557-4567, 2005.

[34] E. Navarro-Sanchez, R. Altmeyer, A. Amara et al., "Dendritic-cell-specific ICAM3-grabbing non-integrin is essential for the productive infection of human dendritic cells by mosquito-cell-derived dengue viruses," EMBO Reports, vol. 4, no. 7, pp. 723-728, 2003.

[35] B. Tassaneetrithep, T. H. Burgess, A. Granelli-Piperno et al., "DC-SIGN (CD209) mediates dengue virus infection of human dendritic cells," Journal of Experimental Medicine, vol. 197, no. 7, pp. 823-829, 2003.

[36] J. L. Miller, B. J. M. DeWet, L. Martinez-Pomares et al., "The mannose receptor mediates dengue virus infection of macrophages," PLoS Pathogens, vol. 4, no. 2, article e17, 2008.

[37] S. T. Chen, Y. L. Lin, M. T. Huang et al., "CLEC5A is critical for dengue-virus-induced lethal disease," Nature, vol. 453, no. 7195, pp. 672-676, 2008.

[38] P. Hilgard and R. Stockert, "Heparan sulfate proteoglycans initiate dengue virus infection of hepatocytes," Hepatology, vol. 32, no. 5, pp. 1069-1077, 2000.

[39] Y. L. Lin, H. Y. Lei, Y. S. Lin, T. M. Yeh, S. H. Chen, and H. S. Liu, "Heparin inhibits dengue-2 virus infection of five human liver cell lines," Antiviral Research, vol. 56, no. 1, pp. 93-96, 2002.

[40] S. Jindadamrongwech, C. Thepparit, and D. R. Smith, "Identification of GRP 78 (BiP) as a liver cell expressed receptor element for dengue virus serotype 2," Archives of Virology, vol. 149, no. 5, pp. 915-927, 2004.

[41] C. Thepparit and D. R. Smith, "Serotype-specific entry of dengue virus into liver cells: identification of the 37kilodalton/67-kilodalton high-affinity laminin receptor as a dengue virus serotype 1 receptor," Journal of Virology, vol. 78, no. 22, pp. 12647-12656, 2004.

[42] J. L. Zhang, J. L. Wang, N. Gao, Z. T. Chen, Y. P. Tian, and J. An, "Up-regulated expression of $\beta 3$ integrin induced by dengue virus serotype 2 infection associated with virus entry into human dermal microvascular endothelial cells,"
Biochemical and Biophysical Research Communications, vol. 356, no. 3, pp. 763-768, 2007.

[43] S. L. Hung, P. L. Lee, H. W. Chen, L. K. Chen, C. L. Kao, and C. C. King, "Analysis of the steps involved in dengue virus entry into host cells," Virology, vol. 257, no. 1, pp. 156-167, 1999.

[44] C. Aoki, K. I. P. J. Hidari, S. Itonori et al., "Identification and characterization of carbohydrate molecules in mammalian cells recognized by dengue virus type 2," Journal of Biochemistry, vol. 139, no. 3, pp. 607-614, 2006.

[45] P. Sakoonwatanyoo, V. Boonsanay, and D. R. Smith, "Growth and production of the dengue virus in C6/36 cells and identification of a laminin-binding protein as a candidate serotype 3 and 4 receptor protein," Intervirology, vol. 49, no. 3, pp. 161-172, 2006.

[46] J. S. Salas-Benito and R. M. Del Angel, "Identification of two surface proteins from C6/36 cells that bind dengue type 4 virus," Journal of Virology, vol. 71, no. 10, pp. 7246-7252, 1997.

[47] J. Salas-Benito, J. R. D. Valle, M. Salas-Benito, I. CeballosOlvera, C. Mosso, and R. M. Del Angel, "Evidence that the $45-\mathrm{kD}$ glycoprotein, part of a putative dengue virus receptor complex in the mosquito cell line $\mathrm{C} 6 / 36$, is a heat-shockrelated protein," American Journal of Tropical Medicine and Hygiene, vol. 77, no. 2, pp. 283-290, 2007.

[48] A. Kuadkitkan, N. Wikan, C. Fongsaran, and D. R. Smith, "Identification and characterization of prohibitin as a receptor protein mediating DENV-2 entry into insect cells," Virology, vol. 406, no. 1, pp. 149-161, 2010.

[49] J. M. Costin, E. Jenwitheesuk, S. M. Lok et al., "Structural optimization and de novo design of dengue virus entry inhibitory peptides," PLoS Neglected Tropical Diseases, vol. 4, no. 6, article no. e721, 2010.

[50] Y. M. Hrobowski, R. F. Garry, and S. F. Michael, "Peptide inhibitors of dengue virus and West Nile virus infectivity," Virology Journal, vol. 2, article 49, 2005.

[51] Q. Y. Wang, S. J. Patel, E. Vangrevelinghe et al., "A smallmolecule dengue virus entry inhibitor," Antimicrobial Agents and Chemotherapy, vol. 53, no. 5, pp. 1823-1831, 2009.

[52] J. M. Yang, Y. F. Chen, Y. Y. Tu, K. R. Yen, and Y. L. Yang, "Combinatorial computational approaches to identify tetracycline derivatives as flavivirus inhibitors," PLoS One, vol. 2, no. 5, article no. e428, 2007.

[53] S. J. F. Kaptein, T. De Burghgraeve, M. Froeyen et al., "A derivate of the antibiotic doxorubicin is a selective inhibitor of dengue and yellow fever virus replication in vitro," Antimicrobial Agents and Chemotherapy, vol. 54, no. 12, pp. 5269-5280, 2010.

[54] M. K. Poh, A. Yip, S. Zhang et al., "A small molecule fusion inhibitor of dengue virus," Antiviral Research, vol. 84, no. 3, pp. 260-266, 2009.

[55] K. Whitby, T. C. Pierson, B. Geiss et al., "Castanospermine, a potent inhibitor of dengue virus infection in vitro and in vivo," Journal of Virology, vol. 79, no. 14, pp. 8698-8706, 2005.

[56] M. P. Courageot, M. P. Frenkiel, C. Duarte Dos Santos, V. Deubel, and P. Desprès, " $\alpha$-Glucosidase inhibitors reduce dengue virus production by affecting the initial steps of virion morphogenesis in the endoplasmic reticulum," Journal of Virology, vol. 74, no. 1, pp. 564-572, 2000.

[57] S. F. Wu, C. J. Lee, C. L. Liao, R. A. Dwek, N. Zitzmann, and Y. L. Lin, "Antiviral effects of an iminosugar derivative on flavivirus infections," Journal of Virology, vol. 76, no. 8, pp. 3596-3604, 2002. 
[58] P. H. Liang, W. C. Cheng, Y. L. Lee et al., "Novel fivemembered iminocyclitol derivatives as selective and potent glycosidase inhibitors: new structures for antivirals and osteoarthritis," ChemBioChem, vol. 7, no. 1, pp. 165-173, 2006.

[59] B. Gu, P. Mason, L. Wang et al., "Antiviral profiles of novel iminocyclitol compounds against bovine viral diarrhea virus, West Nile virus, dengue virus and hepatitis B virus," Antiviral Chemistry and Chemotherapy, vol. 18, no. 1, pp. 49-59, 2007.

[60] J. Chang, L. Wang, D. Ma et al., "Novel imino sugar derivatives demonstrate potent antiviral activity against flavivirusesv," Antimicrobial Agents and Chemotherapy, vol. 53, no. 4, pp. 1501-1508, 2009.

[61] M. M. F. Alen, S. J. F. Kaptein, T. De Burghgraeve, J. Balzarini, J. Neyts, and D. Schols, "Antiviral activity of carbohydratebinding agents and the role of DC-SIGN in dengue virus infection," Virology, vol. 387, no. 1, pp. 67-75, 2009.

[62] M. M.F. Alen, T. de Burghgraeve, S. J.F. Kaptein, J. Balzarini, J. Neyts, and D. Schols, "Broad Antiviral activity of Carbohydrate-binding agents against the four serotypes of dengue virus in monocyte-derived dendritic cells," PLoS One, vol. 6, no. 6, article e21658, 2011.

[63] E. Lee, M. Pavy, N. Young, C. Freeman, and M. Lobigs, "Antiviral effect of the heparan sulfate mimetic, PI-88, against dengue and encephalitic flaviviruses," Antiviral Research, vol. 69, no. 1, pp. 31-38, 2006.

[64] K. I. P. J. Hidari, N. Takahashi, M. Arihara, M. Nagaoka, K. Morita, and T. Suzuki, "Structure and anti-dengue virus activity of sulfated polysaccharide from a marine alga," Biochemical and Biophysical Research Communications, vol. 376, no. 1, pp. 91-95, 2008.

[65] L. Ono, W. Wollinger, I. M. Rocco, T. L. M. Coimbra, P. A. J. Gorin, and M. R. Sierakowski, "In vitro and in vivo antiviral properties of sulfated galactomannans against yellow fever virus (BeH111 strain) and dengue 1 virus (Hawaii strain)," Antiviral Research, vol. 60, no. 3, pp. 201-208, 2003.

[66] L. B. Talarico, C. A. Pujol, R. G. M. Zibetti et al., "The antiviral activity of sulfated polysaccharides against dengue virus is dependent on virus serotype and host cell," Antiviral Research, vol. 66, no. 2-3, pp. 103-110, 2005.

[67] L. B. Talarico and E. B. Damonte, "Interference in dengue virus adsorption and uncoating by carrageenans," Virology, vol. 363, no. 2, pp. 473-485, 2007.

[68] H. Qiu, W. Tang, X. Tong, K. Ding, and J. Zuo, "Structure elucidation and sulfated derivatives preparation of two $\alpha$-dglucans from Gastrodia elata Bl. and their anti-dengue virus bioactivities," Carbohydrate Research, vol. 342, no. 15, pp. 2230-2236, 2007.

[69] C. R. Rees, J. M. Costin, R. C. Fink et al., "In vitro inhibition of dengue virus entry by p-sulfoxy-cinnamic acid and structurally related combinatorial chemistries," Antiviral Research, vol. 80, no. 2, pp. 135-142, 2008.

[70] S. B. Halstead, E. J. O’Rourke, and A. C. Allison, "Dengue viruses and mononuclear phagocytes. II. Identity of blood and tissue leukocytes supporting in vitro infection," Journal of Experimental Medicine, vol. 146, no. 1, pp. 218-229, 1977.

[71] A. P. Durbin, M. J. Vargas, K. Wanionek et al., "Phenotyping of peripheral blood mononuclear cells during acute dengue illness demonstrates infection and increased activation of monocytes in severe cases compared to classic dengue fever," Virology, vol. 376, no. 2, pp. 429-435, 2008.

[72] C. C. Daughaday, W. E. Brandt, J. M. McCown, and P. K. Russell, "Evidence for two mechanisms of dengue virus infection of adherent human monocytes: trypsin-sensitive virus receptors and trypsin-resistant immune complex receptors," Infection and Immunity, vol. 32, no. 2, pp. 469-473, 1981.

[73] S. Taweechaisupapong, S. Sriurairatana, S. Angsubhakorn et al., "Langerhans cell density and serological changes following intradermal immunisation of mice with dengue 2 virus," Journal of Medical Microbiology, vol. 45, no. 2, pp. 138145, 1996.

[74] M. Marovich, G. Grouard-Vogel, M. Louder et al., "Human dendritic cells as targets of dengue virus infection," Journal of Investigative Dermatology Symposium Proceedings, vol. 6, no. 3, pp. 219-224, 2001.

[75] D. H. Libraty, S. Pichyangkul, C. Ajariyakhajorn, T. P. Endy, and F. A. Ennis, "Human dendritic cells are activated by dengue virus infection: enhancement by gamma interferon and implications for disease pathogenesis," Journal of Virology, vol. 75, no. 8, pp. 3501-3508, 2001.

[76] L. J. Ho, J. J. Wang, M. F. Shaio et al., "Infection of human dendritic cells by Dengue virus causes cell maturation and cytokine production," Journal of Immunology, vol. 166, no. 3, pp. 1499-1506, 2001.

[77] P. Y. Lozach, L. Burleigh, I. Staropoli et al., "Dendritic cell-specific intercellular adhesion molecule 3-grabbing nonintegrin (DC-SIGN)-mediated enhancement of dengue virus infection is independent of DC-SIGN internalization signals," Journal of Biological Chemistry, vol. 280, no. 25, pp. 23698-23708, 2005.

[78] D. A. Mitchell, A. J. Fadden, and K. Drickamer, "A novel mechanism of carbohydrate recognition by the C-type lectins DC-SIGN and DC-SIGNR. Subunit organization and binding to multivalent ligands," Journal of Biological Chemistry, vol. 276, no. 31, pp. 28939-28945, 2001.

[79] H. Feinberg, D. A. Mitchell, K. Drickamer, and W. I. Weis, "Structural basis for selective recognition of oligosaccharides by DC-SIGN and DC-SIGNR," Science, vol. 294, no. 5549, pp. 2163-2166, 2001.

[80] B. J. Appelmelk, I. Van Die, S. J. Van Vliet, C. M. J. E. Vandenbroucke-Grauls, T. B. H. Geijtenbeek, and Y. Van Kooyk, "Cutting edge: carbohydrate profiling identifies new pathogens that interact with dendritic cell-specific ICAM-3grabbing nonintegrin on dendritic cells," Journal of Immunology, vol. 170, no. 4, pp. 1635-1639, 2003.

[81] T. B. H. Geijtenbeek, D. S. Kwon, R. Torensma et al., "DCSIGN, a dendritic cell-specific HIV-1-binding protein that enhances trans-infection of T cells," Cell, vol. 100, no. 5, pp. 587-597, 2000.

[82] S. Pöhlmann, J. Zhang, F. Baribaud et al., "Hepatitis C virus glycoproteins interact with DC-SIGN and DC-SIGNR," Journal of Virology, vol. 77, no. 7, pp. 4070-4080, 2003.

[83] A. Marzi, P. Möller, S. L. Hanna et al., "Analysis of the interaction of Ebola virus glycoprotein with DC-SIGN (dendritic cell-specific intercellular adhesion molecule 3-grabbing nonintegrin) and its homologue DC-SIGNR," Journal of Infectious Diseases, vol. 196, no. 2, pp. S237-S246, 2007.

[84] Y. Van Kooyk and T. B. H. Geijtenbeek, "DC-SIGN: escape mechanism for pathogens," Nature Reviews Immunology, vol. 3, no. 9, pp. 697-709, 2003.

[85] J. Banchereau and R. M. Steinman, "Dendritic cells and the control of immunity," Nature, vol. 392, no. 6673, pp. 245252, 1998.

[86] Y. C. Chen and S. Y. Wang, "Activation of terminally differentiated human monocytes/macrophages by dengue virus: productive infection, hierarchical production of innate cytokines and chemokines, and the synergistic effect of lipopolysaccharide," Journal of Virology, vol. 76, no. 19, pp. 9877-9887, 2002. 
[87] A. A. Watson, A. A. Lebedev, B. A. Hall et al., "Structural flexibility of the macrophage dengue virus receptor CLEC5A: implications for ligand binding and signaling," Journal of Biological Chemistry, vol. 286, no. 27, pp. 24208-24218, 2011.

[88] Y. L. Lin, C. C. Liu, H. Y. Lei et al., "Infection of five human liver cell lines by dengue-2 virus," Journal of Medical Virology, vol. 60, no. 4, pp. 425-431, 2000.

[89] S. L. Seneviratne, G. N. Malavige, and H. J. de Silva, "Pathogenesis of liver involvement during dengue viral infections," Transactions of the Royal Society of Tropical Medicine and Hygiene, vol. 100, no. 7, pp. 608-614, 2006.

[90] C. Thepparit, W. Phoolcharoen, L. Suksanpaisan, and D. R. Smith, "Internalization and propagation of the dengue virus in human hepatoma (HepG2) cells," Intervirology, vol. 47, no. 2, pp. 78-86, 2004.

[91] S. Wati, M. L. Soo, P. Zilm et al., "Dengue virus infection induces upregulation of GRP78, which acts to chaperone viral antigen production," Journal of Virology, vol. 83, no. 24, pp. 12871-12880, 2009.

[92] S. Pöhlmann, E. J. Soilleux, F. Baribaud et al., "DC-SIGNR, a DC-SIGN homologue expressed in endothelial cells, binds to human and simian immunodeficiency viruses and activates infection in trans," Proceedings of the National Academy of Sciences of the United States of America, vol. 98, no. 5, pp. 2670-2675, 2001.

[93] A. A. Bashirova, T. B. H. Geijtenbeek, G. C. F. Van Duijnhoven et al., "A dendritic cell-specific intercellular adhesion molecule 3-grabbing nonintegrin (DC-SIGN)-related protein is highly expressed on human liver sinusoidal endothelial cells and promotes HIV-1 infection," Journal of Experimental Medicine, vol. 193, no. 6, pp. 671-678, 2001.

[94] C. W. Davis, H. Y. Nguyen, S. L. Hanna, M. D. Sánchez, R. W. Doms, and T. C. Pierson, "West nile virus discriminates between DC-SIGN and DC-SIGNR for cellular attachment and infection," Journal of Virology, vol. 80, no. 3, pp. 12901301, 2006.

[95] P. Avirutnan, P. Malasit, B. Seliger, S. Bhakdi, and M. Husmann, "Dengue virus infection of human endothelial cells leads to chemokine production, complement activation, and apoptosis," Journal of Immunology, vol. 161, no. 11, pp. 6338-6346, 1998.

[96] T. Hase, P. L. Summers, and K. H. Eckels, "Flavivirus entry into cultured mosquito cells and human peripheral blood monocytes," Archives of Virology, vol. 104, no. 1-2, pp. 129143, 1989.

[97] V. B. Randolph and V. Stollar, "Low pH-induced cell fusion in flavivirus-infected Aedes albopictus cell cultures," Journal of General Virology, vol. 71, no. 8, pp. 1845-1850, 1990.

[98] R. F. Mercado-Curiel, H. A. Esquinca-Avilés, R. Tovar, Á. Díaz-Badillo, M. Camacho-Nuez, and M. D. L. Muñoz, "The four serotypes of dengue recognize the same putative receptors in Aedes aegypti midgut and Ae. albopictus cells," BMC Microbiology, vol. 6, article no. 85, 2006.

[99] R. Perera, M. Khaliq, and R. J. Kuhn, "Closing the door on flaviviruses: entry as a target for antiviral drug design," Antiviral Research, vol. 80, no. 1, pp. 11-22, 2008.

[100] Y. Modis, S. Ogata, D. Clements, and S. C. Harrison, "A ligand-binding pocket in the dengue virus envelope glycoprotein," Proceedings of the National Academy of Sciences of the United States of America, vol. 100, no. 12, pp. 69866991, 2003.

[101] F. A. Rey, F. X. Heinz, C. Mandl, C. Kunz, and S. C. Harrison, "The envelope glycoprotein from tick-borne encephalitis virus at 2 Å resolution," Nature, vol. 375, no. 6529, pp. 291298, 1995.

[102] W. D. Crill and J. T. Roehrig, "Monoclonal antibodies that bind to domain III of dengue virus E glycoprotein are the most efficient blockers of virus adsorption to vero cells," Journal of Virology, vol. 75, no. 16, pp. 7769-7773, 2001.

[103] R. Rajamanonmani, C. Nkenfou, P. Clancy et al., "On a mouse monoclonal antibody that neutralizes all four dengue virus serotypes," Journal of General Virology, vol. 90, no. 4, pp. 799-809, 2009.

[104] J. H. Scherret, J. S. Mackenzie, A. A. Khromykh, and R. A. Hall, "Biological significance of glycosylation of the envelope protein of Kunjin virus," Annals of the New York Academy of Sciences, vol. 951, pp. 361-363, 2001.

[105] J. A. Mondotte, P. Y. Lozach, A. Amara, and A. V. Gamarnik, "Essential role of dengue virus envelope protein N glycosylation at asparagine-67 during viral propagation," Journal of Virology, vol. 81, no. 13, pp. 7136-7148, 2007.

[106] E. Pokidysheva, Y. Zhang, A. J. Battisti et al., "CryoEM reconstruction of dengue virus in complex with the carbohydrate recognition domain of DC-SIGN," Cell, vol. 124, no. 3, pp. 485-493, 2006.

[107] D. J. Vigerust and V. L. Shepherd, "Virus glycosylation: role in virulence and immune interactions," Trends in Microbiology, vol. 15, no. 5, pp. 211-218, 2007.

[108] A. J. Johnson, F. Guirakhoo, and J. T. Roehrig, "The envelope glycoproteins of dengue 1 and dengue 2 viruses grown in mosquito cells differ in their utilization of potential glycosylation sites," Virology, vol. 203, no. 2, pp. 241-249, 1994.

[109] K. Hacker, L. White, and A. M. de Silva, "N-linked glycans on dengue viruses grown in mammalian and insect cells," Journal of General Virology, vol. 90, no. 9, pp. 2097-2106, 2009.

[110] E. Lee, S. K. Leang, A. Davidson, and M. Lobigs, "Both E protein glycans adversely affect dengue virus infectivity but are beneficial for virion release," Journal of Virology, vol. 84, no. 10, pp. 5171-5180, 2010.

[111] F. Guirakhoo, A. R. Hunt, J. G. Lewis, and J. T. Roehrig, "Selection and partial characterization of dengue 2 virus mutants that induce fusion at elevated $\mathrm{pH}$," Virology, vol. 194, no. 1, pp. 219-223, 1993.

[112] E. Lee, R. C. Weir, and L. Dalgarno, "Changes in the dengue virus major envelope protein on passaging and their localization on the three-dimensional structure of the protein," Virology, vol. 232, no. 2, pp. 281-290, 1997.

[113] J. E. Bryant, A. E. Calvert, K. Mesesan et al., "Glycosylation of the dengue 2 virus E protein at N67 is critical for virus growth in vitro but not for growth in intrathoracically inoculated Aedes aegypti mosquitoes," Virology, vol. 366, no. 2, pp. 415423, 2007.

[114] K. M. Rogers and M. Heise, "Modulation of cellular tropism and innate antiviral response by viral glycans," Journal of Innate Immunity, vol. 1, no. 5, pp. 405-412, 2009.

[115] W. B. Klimstra, E. M. Nangle, M. S. Smith, A. D. Yurochko, and K. D. Ryman, "DC-SIGN and L-SIGN can act as attachment receptors for alphaviruses and distinguish between mosquito cell- and mammalian cell-derived viruses," Journal of Virology, vol. 77, no. 22, pp. 12022-12032, 2003.

[116] C. O. Nicholson, J. M. Costin, D. K. Rowe et al., "Viral entry inhibitors block dengue antibody-dependent enhancement in vitro," Antiviral Research, vol. 89, no. 1, pp. 71-74, 2011.

[117] A. C. Sayce, J. L. Miller, and N. Zitzmann, "Targeting a host process as an antiviral approach against dengue virus," Trends in Microbiology, vol. 18, no. 7, pp. 323-330, 2010. 
[118] A. Mehta, S. Ouzounov, R. Jordan et al., "Imino sugars that are less toxic but more potent as antivirals, in vitro, compared with N-n-nonyl DNJ," Antiviral Chemistry and Chemotherapy, vol. 13, no. 5, pp. 299-304, 2002.

[119] W. Schul, W. Liu, H. Y. Xu, M. Flamand, and S. G. Vasudevan, "A dengue fever viremia model in mice shows reduction in viral replication and suppression of the inflammatory response after treatment with antiviral drugs," Journal of Infectious Diseases, vol. 195, no. 5, pp. 665-674, 2007.

[120] J. Chang, W. Schul, T. D. Butters et al., "Combination of $\alpha$-glucosidase inhibitor and ribavirin for the treatment of dengue virus infection in vitro and in vivo," Antiviral Research, vol. 89, no. 1, pp. 26-34, 2011.

[121] N. Shibuya, I. J. Goldstein, E. J. Van Damme, and W. J. Peumans, "Binding properties of a mannose-specific lectin from the snowdrop (Galanthus nivalis) bulb," Journal of Biological Chemistry, vol. 263, no. 2, pp. 728-734, 1988.

[122] H. Kaku, E. J. M. Van Damme, W. J. Peumans, and I. J. Goldstein, "Carbohydrate-binding specificity of the daffodil (Narcissus pseudonarcissus) and amaryllis (Hippeastrum hybr.) bulb lectins," Archives of Biochemistry and Biophysics, vol. 279, no. 2, pp. 298-304, 1990.

[123] N. Shibuya, I. J. Goldstein, J. A. Shafer, W. J. Peumans, and W. F. Broekaert, "Carbohydrate binding properties of the stinging nettle (Urtica dioica) rhizome lectin," Archives of Biochemistry and Biophysics, vol. 249, no. 1, pp. 215-224, 1986.

[124] J. J. Hung, M. T. Hsieh, M. J. Young, C. L. Kao, C. C. King, and W. Chang, "An external loop region of domain III of dengue virus type 2 envelope protein is involved in serotype-specific binding to mosquito but not mammalian cells," Journal of Virology, vol. 78, no. 1, pp. 378-388, 2004.

[125] R. M. Marks, H. Lu, R. Sundaresan et al., "Probing the interaction of dengue virus envelope protein with heparin: assessment of glycosaminoglycan-derived inhibitors," Journal of Medicinal Chemistry, vol. 44, no. 13, pp. 2178-2187, 2001.

[126] C. A. Pujol, J. M. Estevez, M. J. Carlucci, M. Ciancia, A. S. Cerezo, and E. B. Damonte, "Novel DL-galactan hybrids from the red seaweed Gymnogongrus torulosus are potent inhibitors of herpes simplex virus and dengue virus," Antiviral Chemistry and Chemotherapy, vol. 13, no. 2, pp. 83-89, 2002.

[127] X. K. Tong, H. Qiu, X. Zhang et al., "WSS45, a sulfated $\alpha$ D-glucan, strongly interferes with Dengue 2 virus infection in vitro," Acta Pharmacologica Sinica, vol. 31, no. 5, pp. 585$592,2010$. 


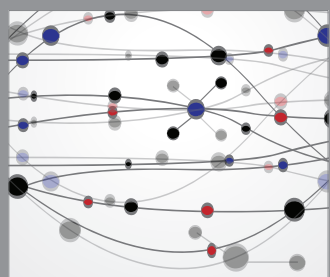

The Scientific World Journal
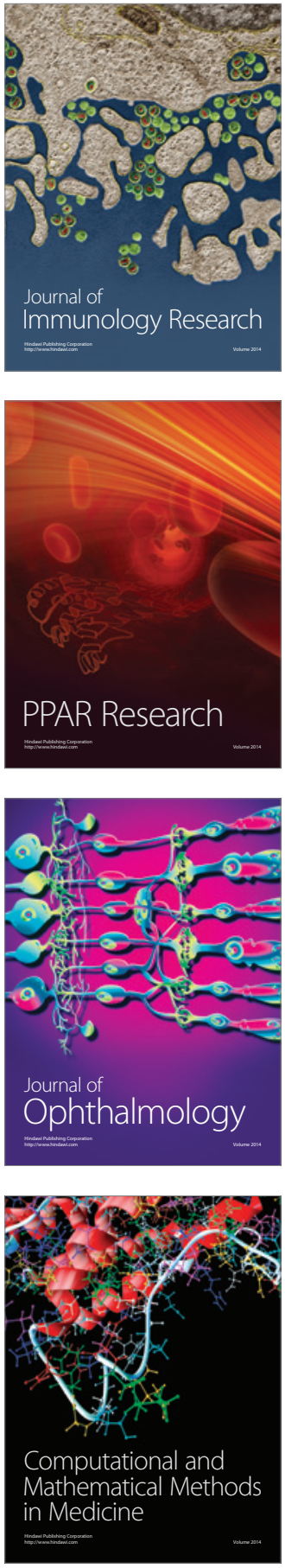

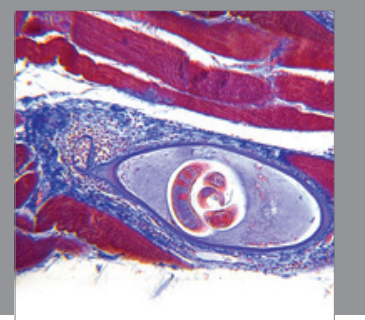

Gastroenterology

Research and Practice
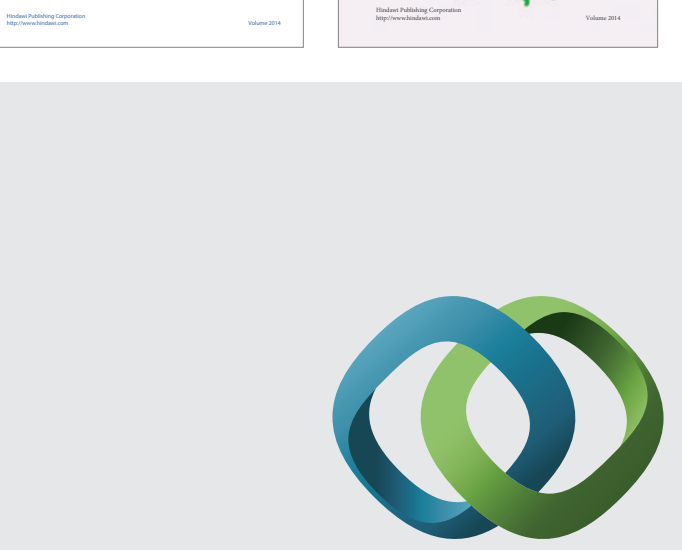

\section{Hindawi}

Submit your manuscripts at

http://www.hindawi.com
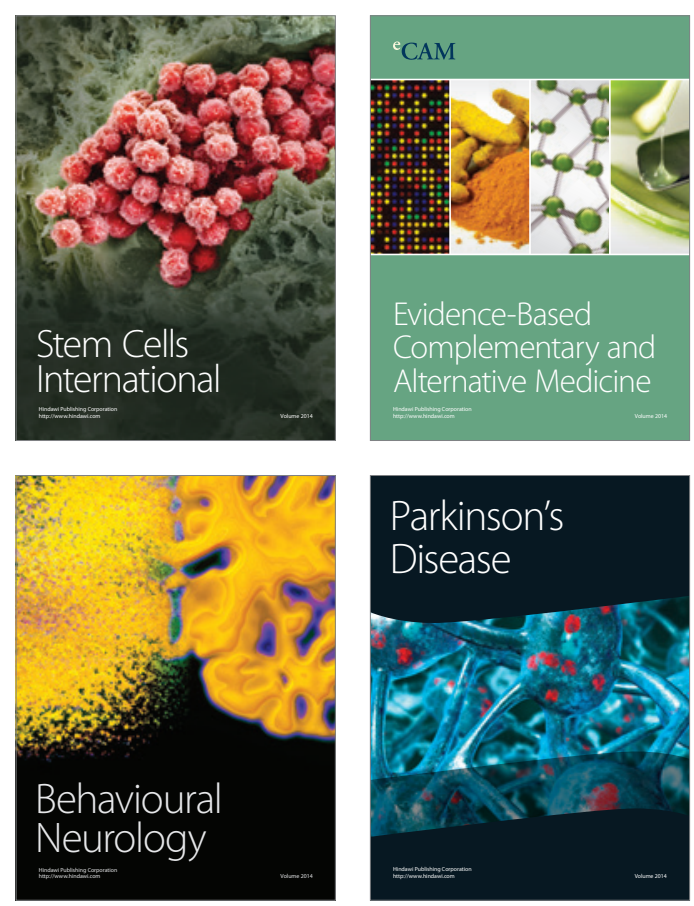

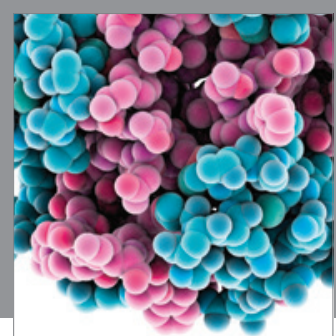

Journal of
Diabetes Research

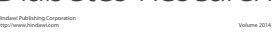

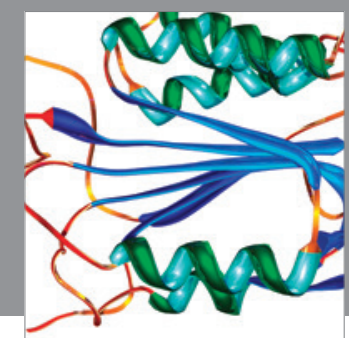

Disease Markers
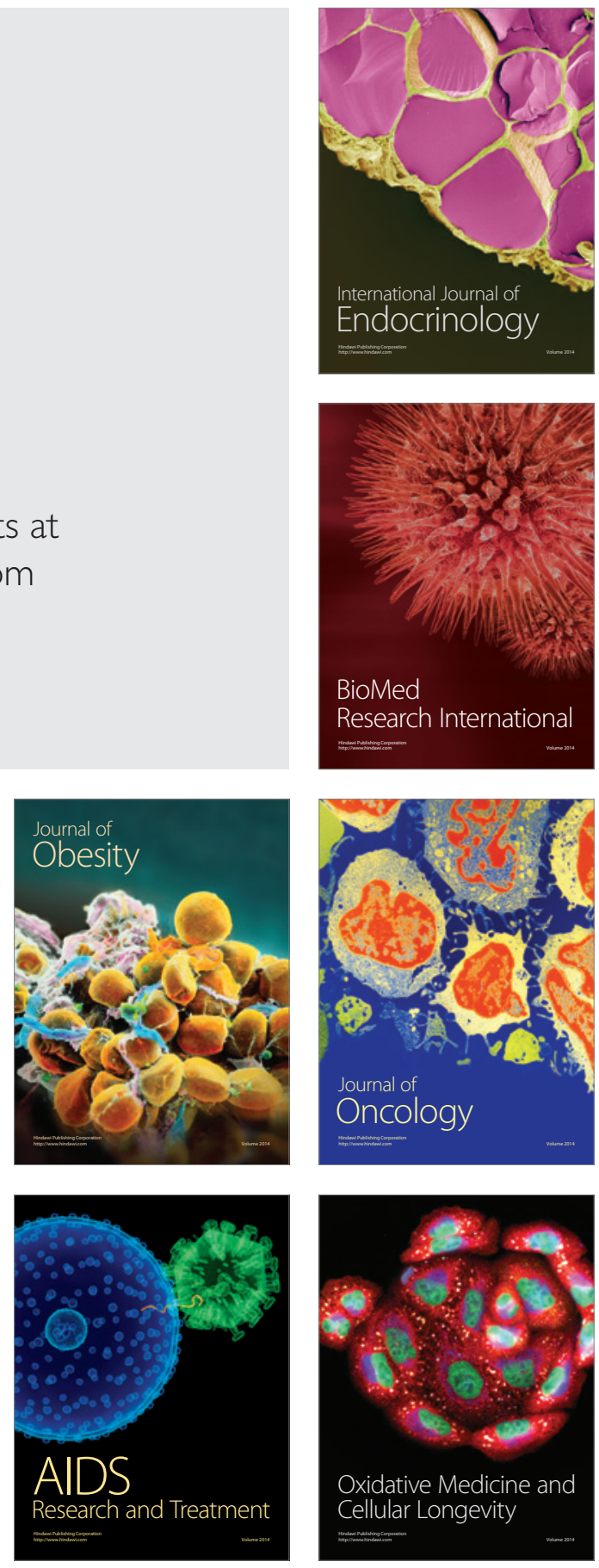